\title{
Health Care Delivery Model of Childhood Epilepsy to Reduce Treatment Gap in an Outreach- Financially-Constrained District in Pakistan
}

\author{
Muhammad Akbar Malik ${ }^{1 *}$, Nadeem Shabbir ${ }^{2}$, Arshad Rafiq $^{3}$, Ahmad Omar Virk ${ }^{4}$ \\ ${ }^{1}$ In charge Top-Down-Bottom-Up-Childhood-Epilepsy-Programme, The Brain Associates Lahore, Pakistan \\ ${ }^{2}$ Associate Program Director, Department of Pediatrics, Nassau University Medical Center, USA \\ ${ }^{3}$ Visiting Consultant Pediatric neurologist, The Brain Assciates Lahore, Pakistan \\ ${ }^{4}$ Pediatric neurologist- Children's Hospital Faisalabad, Pakistan
}

*Corresponding Author: Muhammad Akbar Malik, FRCP, In charge Top-Down-Bottom-Up-ChildhoodEpilepsy-Programme, The Brain Associates Lahore, Pakistan, Email: docmalikpk2000@yahoo.co.in

\begin{abstract}
Background: In order to tackle the considerable treatment gap for childhood epilepsy in many low-and middle-income countries (LMICs), a task sharing model is recommended whereby care is integrated into primary health services in outreach financially constrained districts. However, there are limited data on implementation and impact of such services in poor settings. Our study aimed to explore the perspectives of service users on the clinical-effectiveness and cost-effectiveness of childhood epilepsy treatment received in a task-shared model in an outreach-financially constrained district Bhakhar-Pakistan.
\end{abstract}

Methods: A qualitative interventional case control study was carried out using the center records and interviews with 240 children with epilepsy (160 being followed at the community childhood epilepsy center and 80 (control) receiving care as usual). Most of the care received was focused on medication provision with limited information provided on how to manage their illness and its effects.

Results: Among the children getting free AEDs and monthly pediatric neurology consultations, AEDs adherence of $85 \%$ and treatment gap of $20 \%$ was documented. In comparison among the children receiving epilepsy treatment care as usual (control), AEDs adherence was $38 \%$ and childhood treatment gap, according to ILAE, was $82.5 \%$. Childhood epilepsy treatment from local community center was 202 times cost-effective as compared to such treatment from Lahore. By integration and implementation of childhood epilepsy center in primary health financial constraints and issue of sustainability could be easily sorted out.

Conclusion: Task-sharing improved the overall care of childhood epilepsy. Nonetheless, promotion of community involvement and family engagement were highlighted as areas requiring further improvement. Future work on implementing childhood epilepsy care models in LMIC contexts is warranted.

Keywords: Epilepsy, Implementation, Task-sharing, Primary health services, Community health care, ILAE, Bhakhar, Pakistan.

\section{INTRODUCTION}

The most contributing factors to the epilepsy treatment gap are the following: i) inadequate skilled healthcare manpower, ii) high treatment costs, iii) limited or no antiepileptic drug access, and iv) unfavorable cultural beliefs. These factors jointly play a role in most regions of low-middle-income-countries (LMICs), where the treatment gap is over $75 \%$ [1]. A potential strategy to reduce this treatment gap is the detection, monitoring, and treatment of epilepsy with community-based rehabilitation (CBR).
Offering diagnosis, monitoring, and treatment is only one aspect of the CBR strategy. Recent studies have shown that up to $70-80 \%$ of newly diagnosed epilepsy patients can be treated successfully (i.e. seizures completely controlled) by low-cost community-based strategy using anti-epileptic drugs (AEDs) [2-4] Acknowledging epilepsy as a neglected condition by the World Health Organization (WHO) in 2004 has led to increased emphasis on the development of adequate treatment strategies in LMICs [5, 6]. 
Health Care Delivery Model of Childhood Epilepsy to Reduce Treatment Gap in an OutreachFinancially-Constrained District in Pakistan

Although cost-effective epilepsy treatments are available and accurate diagnosis can be made without technological equipment, a vast majority of individuals with epilepsy in many resource poor regions do not receive treatment (i.e. have high treatment gap) [7-9]. Treatment of childhood epilepsy in low-income countries is a challenge considering the lack of trained medical personals, priority, financial resources, availability of antiepileptic drugs, and cultural beliefs. Prior anecdotal and descriptive estimates suggest a treatment gap of more than $80 \%$ in many low-income countries $[10,12]$. In agreement in 2014, we documented by snapshot study that $58 \% \mathrm{CWE}$ were nonadherent to the prescribed AEDs and $92 \%$ had childhood epilepsy treatment gap (CETG) [13, 14]. Large community based trials in Brazil and China have demonstrated that epilepsy can be treated with inexpensive and effective drugs at the community level by primary health professionals with basic training[15]. The Demonstration Projects have been successful in implementing treatment and management of convulsive forms of epilepsy in rural areas of the LMICs. Physicians with basic training are shown to be able to treat people with epilepsy. This cost-effective approach was successful in reducing the epilepsy treatment gap [16].

In these lines we hypothesized that establishment of primary health multicomponent intervention childhood epilepsy center (PHMCICEC) in Bhakhar, an outreach financially constrained district in Punjab-Pakistan, would improve AEDs adherence and would bridge the huge treatment gap among children with epilepsy. After 4 years of monthly free childhood epilepsy camps, telepediatric neurology support and after two years of integration and implementation of childhood epilepsy (CE) into already existing primary health care center, this study will therefore evaluate the feasibility and (cost-)effectiveness of the primary care multicomponent intervention childhood epilepsy center (PHMCICEC), in comparison with care as usual (CAU). As the success of any intervention is a consequence of it being sustainable in the long term, this report also presents the lessons derived for the development of an effective and sustainable framework for epilepsy care (PHMCICEC) and scale-up to improve care of CWE in outreach financially constrained district in Pakistan

\section{METHODS}

This study will consist of two parts, each with its own research questions:

\subsection{Economic Evaluation}

What are the cost-effectiveness and the costutility of the PHMCICEC in comparison with CAU from a societal perspective?

\subsection{Clinical Effectiveness}

Is multi-component intervention childhood epilepsy center (MCICEC), through integration of childhood epilepsy care in primary health care (PHC), empowering it through combination of free consultations, antiepileptic drugs (AEDs), monthly pediatric neurology camps (management/ education program) with eHealth interventions were assessed for effective in anti-epileptic drugs (AEDs) adherence, bridging the treatment gap (TG) and improving epilepsy seizure control in comparison with care as usual (CAU) in an outreach financiallyconstrained district.

\section{DESIGN}

A randomized case controlled trial (RCT) with two parallel groups of CWE:1) children diagnosed, commenced $\mathrm{AED}(\mathrm{s})$ and being followed at MCICEC and 2, children getting care as usual (control), as naturally as possible was conducted to compare the efficacy of MCICEC with CAU in CWE. The AED(s) were commenced at least 3 months prior to the study, among the intervention group and the control group, after which patients in the control group have the opportunity to receive the MCICEC outside the study. The study has been approved by the Ethics Committee of the Brain Associates Lahore.

\subsection{Participants and Recruitment Procedure}

Children diagnosed with epilepsy, commenced AEDs at least $\geq 3$ months back and being followed at TDBUCEC Bhakhar, along with a primary caregiver(s), were approached for study participation from the free pediatric neurology camp held at two noncontiguous community centers. Participants were $\leq 18$ years of age, diagnosed with epilepsy and prescribed at least one AED. To complete questionnaires and assent/consent forms, families had to read/speak Suraikee (local language), which was later translated into English. Exclusion criteria included diagnosis of epilepsy less than three months back or who were not being followed in 
Health Care Delivery Model of Childhood Epilepsy to Reduce Treatment Gap in an OutreachFinancially-Constrained District in Pakistan

primary health multicomponent childhood epilepsy center (PHMCICEC), or the family living >100 miles away from Bhakhar City. In collaboration with the childhood epilepsy team working at PHMCICEC, potential participants and their caregivers meeting eligibility criteria were identified by the trained research assistants with significant experience recruiting families with children with epilepsy.

Recruitment occurred during free childhood epilepsy camp visits. The trained research assistant approached families, provided a thorough overview of the study, including study procedures, benefits, and risks, along with answering any questions. Caregiver/guardian participants provided verbal consent, and verbal assent was obtained from older children. Once consent/assent was obtained, caregivers completed baseline assessment questionnaires. Caregivers also completed several questionnaires, which were used to measure feasibility and acceptability, psychosocial outcomes (e.g., quality of life) and financial constraints. With the exception of feasibility and clinical effectiveness, these questionnaires were not analyzed for purposes of the current study. This study was divided into two phases; 1) Assessment of MCICEC integration into primary health care centre and its sustainability and 2) clinical effectiveness of PHMCICEC in improving AEDs adherence and decreasing the childhood epilepsy treatment gap (CETG).

\subsection{Setting and Recruitment}

The settings for the implementation of the PHMCICEC care plan in Pakistan was Bhakhar district, located $420 \mathrm{~km}$ south of the capital city Lahore of Punjab province. This city has district headquarter hospital and paediatric department headed by a qualified paediatrician but no paediatric neurologist is available in the city. There are many private hospitals and clinics providing all sorts of paediatric services. Also, there are traditional healers, who are thought to possess medicinal antidotes to the occurrence of epilepsy and other neurological diseases in the children. This study is a collaboration between Top-Down-Bottom-Up-Childhood-EpilepsyProgram under the auspices of the brain Associates Lahore and the PHMCICEC Bhakhar city on 7th and 8th December 2018. The study is conducted in PHMCICEC and children attending free pediatric neurology camps at two non-contiguous community centers in Bhakhar city.
The following issues were considered before and while implementing the model: initiating public education and advocacy activities, estimating the size of the problem , providing professional education including development of training materials, developing a referral system ,choosing a suitable drug, ensuring a regular drug supply, encouraging stakeholder participation, providing continued monitoring and providing supportive legislation. While all of the above considerations were taken into account in the design of this childhood epilepsy care programme, the local issues were not discounted. Implementation of PHMCICEC in Pakistan commenced in March of 2014 when this strategy was launched voluntarily by Prof. Malik (1st author), with aim to improve the quality of childhood epilepsy care through the integration and implementation childhood epilepsy in primary health care. However, two years back (December, 2016) PHMCICEC was integrated and implemented into charity primary care center in this city.

The patients willing in participating had a faceto-face interview with all possible available records with one of the researchers (local or visiting ), in which patients had the opportunity to ask questions and in which inclusion and exclusion criteria was checked either by the researchers during the meeting or afterwards in consultation with clinicians. During the meeting, patients were informed about the study and that they will be randomly assigned either to the intervention or control group. During the two days of attending outpatient camps, an informed verbal consent was sought from the $\mathrm{CWE} /$ parents. The researcher and patients were allocated randomly to either the intervention or control group.

\subsection{Primary Care Multi-Component Intervention Childhood Epilepsy Center (Pcmcicec) Bhakhar}

The TDBUCEP is actively involved in outreach and education for the community and healthcare professionals. Our goal is to help the public understand epilepsy, which in turn will make life a bit easier for CWE and their family members. Our complimentary programs and services include:

- Integration and implementation of childhood epilepsy in local community charity primary health care centers (PHMCICEC). 
Health Care Delivery Model of Childhood Epilepsy to Reduce Treatment Gap in an OutreachFinancially-Constrained District in Pakistan

- Skype/mobile telepediatric neurology consultations and supporting PHMCICEC.

- Special events like one whole day free pediatric neurology camps in different outreach, financially- constrained communities.

Our center seeks not only to enhance the general awareness of epilepsy, but also to educate the public on first-aid procedures to follow if they see or experience a seizure. For the patient management to be optimised in the patient's own community, we began to explore collaboration with local non-specialist hospitals, community health centers and primary health centers to provide an outreach service in an identical manner like other developments of adequate treatment strategies in low-and middleincome countries (LMICs) [17, 18], thus avoiding expensive travelling to the specialist hospitals/clinics in metropolitan cities.

We used Rukhsana Memorial Primary Health Care building, a community based charity primary health center (CBCPHC) for the detection, monitoring, and treatment of childhood epilepsy (MCICEC).After the struggle of 2 years, we were able to convince this charity organization to integrate childhood epilepsy center into this CBPHC, just 500 meters from District Headquarter Hospital in Bhakhar city, 3 stories very specious multipurpose built building on the main road in more than one acre compound

We travel monthly from Lahore to Bhakhar the night before the camp as a team (pediatric neurologists, fellows of pediatric neurology and EEG technologists) to have one whole day camp in noncontiguous localities for pediatric neurology problems with special emphasis on childhood epilepsy (i.e. multi component interventional project; Top-Down: outreach clinics, Bottom-UP empowerment of local community, camps in different noncontiguous localities: mobile epilepsy services to remind, education, awareness and Skype/mobile consultations: Telepaedsneurology services). We provide ongoing personnel and volunteer training at all levels to ensure consistency in service delivery. We have trained pediatrician, nurses, medical and paramedical staff already working in this PHMCICEC that is now fully computerized, including its pharmacy and basic laboratory. A local network of community volunteers has been trained with ongoing training to provide education, good quality antiepileptic drugs, and to motivate the CWE/care takers for clinical follow-up. So we have only invested in training, education and motivation of local workforce, along with our volunteer initiative. This was largely due to an increase in the number of donations and legacies of the local community leaders. In addition to our monthly one whole day of training and consultations of children with neurological disorders, we provide Video-EEG (VEEG) interpretation support, Skype call support and mobile phone advice as and when required.

Financial records were reviewed to establish expenditures on medical supplies, program support costs and staff emoluments for next six months and further donors were sought in the community to assess the sustainability of the programme dependent the on community participation and making it to be societal as well as integrated into primary health care through periodical evaluation. Antiepileptic drugs are provided free of charge, Moreover, drug supplied are stored for next six months, so the patients who had been started AEDs may not face an increased risk of seizures/status epilepticus. The MCICEC and primary health care in this center share resources and work very closely together, providing a continuum of care for childhood epilepsy and primary health care in the community to adults and children. This center had been redesignated by consensus as the additional paediatric epilepsy centre because of its performance, personnel, purpose-built infrastructure with geographic integrity, and it's highly developed complementary services. Patients and caregivers had the opportunity to discuss their experiences related to the clinicaleffectiveness in terms of adherence to $\operatorname{AED}(s)$ and bridging the CETG along with costeffectiveness of the interventions by PHMCICEC. The idea is finding ways to work together to strengthen existing programs and identifying innovative approaches to coordinate use of resources which are critical in responding to childhood epilepsy care in financially constrained community.

\subsection{Control Group}

These are CWE visiting the free community pediatric neurology camps but without any local community intervention. After study enrolment, they will be offered to get free $\mathrm{CE}$ care from the PHMCICEC, without any prejudice. 
Health Care Delivery Model of Childhood Epilepsy to Reduce Treatment Gap in an OutreachFinancially-Constrained District in Pakistan

\subsection{Cost-Effectiveness}

To assess the cost-effectiveness of the PHMCICEC, outcome assessments were done for the both groups: being followed at PHMCICEC and getting care as usual (CAU). The cost would include direct and indirect cost expenses by the parents of CWE seeking their treatment from Lahore and the cost bearded by the community center in provision of free AEDs and free pediatric neurology consultations.

\subsection{Clinical-Effectiveness}

The following outcomes are defined:

- Adherence to $\operatorname{AED(s):~Adherence~is~the~}$ primary determinant of the effec1tiveness and defined as "the extent to which an individual's behavior regarding taking medications, following a diet, and performing lifestyle changes follows agreed recommendations from a health-care provider'[19]The cutoff of $85 \%$ for adherence by self report was based on a study by Lisk et al [20].

- Bridging the childhood epilepsy treatment gap (CETG): The TG is defined as the number of people with active epilepsy not on treatment (diagnostic and therapeutic) or on inadequate treatment according to ILAE, expressed as a percentage of the total number with active epilepsy [21.].

\section{ECONOMIC EVALUATION}

This evaluation primarily adopted a healthcare perspective with the cost of providing care for participants in the two treatment groups over follow-up being compared. We examined such an intervention's clinical- and cost-effectiveness. The study evaluated patients that were offered a comprehensive care package, which included; (a) clinical assessment and commencement of AEDs by primary health care (PHC) workers following the modified mhGAP Intervention Guide (after receiving a 10-day training); (b) Education and therapeutic support through individual or family counseling and patient support groups (PSGs) by community counselors (after receiving a 21-day training, in addition to a base training in counseling); and (c) arranging face to face monthly consultations for complicated cases with monthly visiting pediatric neurology teams from Lahore, ensuring optimal follow-up care. Costminimisation analysis (CMA) is a special form of cost-effectiveness analysis and the simplest form of economic evaluation used in this study. Costs are expressed in monetary units and the patient outcome is assumed to be the same in both/all of the intervention groups evaluated. We used this effectiveness in improving AED(s) adherence and bridging the treatment gap of childhood epilepsy. Hence, the object of this type of analysis is to identify the least expensive alternative. Process evaluation was performed to assess whether the PHMCICEC has delivered according to protocol and has met its objectives.

The economic evaluation was performed from a societal perspective, and was consisting of a cost-effectiveness analysis (CEA) and a costminimization analysis (CMA). We distinguish four cost categories: intervention costs, healthcare sector costs, costs for the patient and family, and productivity costs. Intervention costs will be defined as all costs related to the PHMCICEC including travel costs, personal costs, material costs, e-Health tools (i.e. Skype/ mobile phones) costs and housing costs. Healthcare and patient costs will be estimated using a questionnaire regarding healthcare resource utilization and productivity losses. A comparison between PHMCICEC and CAU will is made in terms of incremental costs and incremental effects in addition to the single consultation for a child with epilepsy/neurology problem from Lahore, a cosmopolitan city 420 $\mathrm{Km}$. from Bhakhar city. To measure the use of health care resources at PHMCICEC including all activities related to childhood epilepsy, we gather data from PHMCICEC and for each patient at two free pediatric neurology camps

\section{Statistical AnalyseS}

Descriptive statistics describe the characteristics of those recruited into the treatment groups, those retained at follow-up and the epilepsy care they received. Logistic regression tested for the significance of any differences between the groups. Odds-ratios (OR) and 95\% confidence intervals (CI) are presented. A P-value of $<0.05$ was considered statistically significant.

\section{Results}

An alternative approach to using costeffectiveness data to set intervention priorities is to interpret the cost-effectiveness ratio as the "price" of equivalent units of health using different interventions cost-effectiveness. 
Health Care Delivery Model of Childhood Epilepsy to Reduce Treatment Gap in an OutreachFinancially-Constrained District in Pakistan

\subsection{Recruitment and Treatment Groups' Equivalence at Baseline}

Two hundred and eighty eligible CWE were identified and 240 agreed to participate. One hundred and $160(66.6 \%)$ patients were randomized from those being intervened at PHMCICEC, which included diagnosis, commencement of AEDs and monthly followup for free consultations and provision of AEDs. Eighty (33.4\%) CWE were randomized to care as usual (control) without any PHMCICEC intervention. The average survey duration for each patient was 15 to 20 minutes (standard

Table1: Demographic information of study cohorts of children with epilepsyby age \& gender in BhakharPakistan $(N=240)$

\begin{tabular}{|c|c|c|c|c|c|c|}
\hline \multicolumn{4}{|c|}{$\begin{array}{l}\text { Children with epilepsy following at PHMCICEC } \\
(\mathrm{n}=160,100 \%)\end{array}$} & \multicolumn{3}{|c|}{$\begin{array}{l}\text { Children with epilepsy following at PHMCICEC } \\
(\mathrm{n}=160,100 \%)\end{array}$} \\
\hline Age & Male & Female & Total $(\%)$ & Total $(\%)$ & Female & Male \\
\hline 6 Mon - 2 yrs & 18 & 15 & $33(20.65 \%)$ & $16(20 \%)$ & 6 & 10 \\
\hline$>2$ yrs - 5 yrs & 22 & 10 & $32(20 \%)$ & $18(22.5 \%)$ & 8 & 10 \\
\hline$>5$ yrs -10 yrs & 34 & 24 & $58(36.25 \%)$ & $26(32.5 \%)$ & 12 & 14 \\
\hline$>10 \mathrm{yrs}-15 \mathrm{yrs}$ & 10 & 15 & $25(15.6 \%)$ & $14(17.5 \%)$ & 4 & 10 \\
\hline$>15$ yrs -18 yrs & 04 & 08 & $12(7.5 \%)$ & $06(7.5 \%)$ & 4 & 2 \\
\hline Total: $160(100 \%)$ & $88(55 \%)$ & $72(45 \%)$ & $160(100 \%)$ & $80(100 \%)$ & $34(42.5 \%)$ & $46(57.5 \%)$ \\
\hline
\end{tabular}

\subsubsection{Treatment Coverage and Cost- Effectiveness of MCICEC}

The registry record of PHMCICEC showed that $2500 \mathrm{CWE} /$ recurrent convulsions are registered with this center integrated in Rukhsana Shafqat Memorial Primary Heath Care Center Bhakhar (RSMPHCB) and on the average 700 CWE get free consultations and AEDs monthly from this center. As can be seen in Table 2, the geographic and population sizes of the catchment area in Bhakhar district is very large. Yet, the number of CWE receiving care from the PHMCICEC under the auspices of TDBUCEP, are reaching only small fraction of those in need of care. Assuming that about $1 \%$ of a given population $\leq 18$ years of age will be suffering from childhood epilepsy (CE) at any given time [21], one can estimate that about 7,000 CWE are in need of CE services; in addition there will be some CWE from the contiguous districts.

Together, these data suggest that, according to the face-to-face interview among the $80 \mathrm{CWE}$ attending free pediatric neurology camps but not being followed at PHMCICEC Bhakhar were seeking treatment: 65(81.25\%) from Lahore, 10(12.5\%) from Multan and 5(6.25\%) from Bhakhar or no treatment. The expenses for each consultation from Lahore and Multan (another cosmopolitan city) were equal, but in Bhakhar deviation: 8.4), and this analysis was of adherence/non-adherence to AEDs and factors associated with promoting drug adherence and treatment gap of childhood epilepsy according to ILAE. The age range of the patients was 6 months to 18 years (mean: 10+3.4years). There was a male preponderance $(134,58 \%)$ with a male: female ratio of 1.26:1. Additional patient demographic information is presented in Table1. The co-primary outcomes were the differences between the intervention and control for 1) treatment cost, 2) adherence to AEDs and 3) treatment gap. no trained medical personal for CWE was available other than the PHMCICEC.

On the average cost of the single consultation from the cosmopolitan cities is 16000 PRS (Table 3), in addition to costly undue private investigations and newer AEDs. Whereas by integration and implementing PHMCICEC in RSMPHCB the additional cost to the dedication of the visiting and local teams are: one additional nurse, PRS 25000, one additional computer operator 20000 PRS, solely for taking care of CWE. Addition of this staff along with training of the already working pediatrician, physician, medical and paramedical staff has improved the overall functioning of RSMPHCB. The voluntary cost of the monthly visiting team is 15000 PRS supported by The Brain Associates Lahore; cost of monthly provision of free AEDs is 500 PRS (from local donations): making total additional cost of 25000+ $15000+15000+500$ (55500 PRS). The average monthly cost of the locally treated 700 CWE from Lahore or Multan would be 11,200,000 PRS (PHMCICEC 202 time's costeffectiveness).

\subsubsection{Effect of PHMCICEC Intervention on Aeds Adherence}

Primary outcomes were daily "taking adherence" (proportion of prescribed doses taken) and "timing adherence" (proportion of 
Health Care Delivery Model of Childhood Epilepsy to Reduce Treatment Gap in an OutreachFinancially-Constrained District in Pakistan

prescribed doses taken within 1 hour before to 2 hours after the prescribed dosing time), as measured by self reporting method. We examined three main types of interventions by MCICEC: i) education and counseling of participants about topics such as epilepsy and medication used to control epilepsy, ii) behavioral interventions such as asking epileptic patients to link the intention of taking their medication with a particular time, place and other routine activity and iii) the use of more than one intervention (monthly free pediatric neurology consultations and provision of free AEDs). Such interventions were not reported among the control group.

The study enrolled 240 children and there were 95(39.6\%) CWE $\leq 05$ years of age. Among the 240 children and adolescents with epilepsy who were interviewed, 160 (66.6\%) reported seeking treatment from MCIUCEC and 80(33.4\%) were diagnosed commenced on $\mathrm{AED}(\mathrm{s})$ from different sources including faith healers,

physicians, and government health facilities. The average survey duration for each patient was 15 to 20 minutes (standard deviation: 8.4), and this analysis was of adherence/nonadherence to AEDs and factors associated with promoting drug adherence.

The age range of the patients was 4 months to 18 years (mean: $10+3.4$ years). There was a male preponderance $(134,58 \%)$ with a male: female ratio of $1.26: 1$. Of the total 240 patients, $82(34 \%)$, were nonadherent and $158(66 \%)$ were adherent to the prescribed AEDs for different reasons. Among the $160 \mathrm{CWE}$ commenced $\operatorname{AED}(\mathrm{s})$ and being followed at PHMCIUCEC, $136(85 \%)$ were adherent, while 24(15\%) were nonadherent to the prescribed drugs. While among the $80 \mathrm{CWE}$ not being treated and followed at the center, 50(62.5\%) were nonadherent and only $30(27.5 \%)$ were adherent to the prescribed $\operatorname{AED}(\mathrm{s})$. Additional patient demographic information is presented in Table2.

Table2: Distribution of children with epilepsy and nonadherence to AEDs by age \& gender in BhakharPakistan (N=240)

\begin{tabular}{|c|c|c|c|c|c|c|c|c|}
\hline $\begin{array}{l}\text { Epileptic Patien } \\
\text { Center }(\mathrm{n}=\mathbf{1 6 0 , 1}\end{array}$ & $\begin{array}{l}\text { ts } \text { Fo } \\
00 \%)\end{array}$ & ing at & Top-Dow & ttom & $\begin{array}{l}\text { Epileptic P } \\
\text { Bottom-Up }\end{array}$ & $\begin{array}{l}\text { tients Not } \\
\text { Center }(\mathrm{N}=\end{array}$ & $\begin{array}{l}\text { ollowing } \\
0,100 \%)\end{array}$ & p-D \\
\hline Age & Male & Female & Total $(\%)$ & Nonad (\%) & Nonad.(\%) & Total $(\%)$ & Female & Male \\
\hline 6 Mon - 2 yrs & 18 & 15 & $33(20.65 \%)$ & $06(3.50 \%)$ & $10(12.5 \%)$ & $16(20 \%)$ & 6 & 10 \\
\hline$>2$ yrs -5 yrs & 22 & 10 & $32(20 \%)$ & $04(2.50 \%)$ & $12(15 \%)$ & $18(22.5 \%)$ & 8 & 10 \\
\hline$>5$ yrs -10 yrs & 34 & 24 & $58(36.25 \%)$ & $08(5 \%)$ & $16(20 \%)$. & $26(32.5 \%)$ & 12 & 14 \\
\hline$>10$ yrs -15 yrs & 10 & 15 & $25(15.6 \%)$ & $04(2.50 \%)$ & $10(12.5 \%)$ & $14(17.5 \%)$ & 4 & 10 \\
\hline$>15$ yrs -18 yrs & 04 & 08 & $12(7.5 \%)$ & $02(2.50 \%)$ & $02(2.5 \%)$ & $06(7.5 \%)$ & 4 & 2 \\
\hline Total: $160(100 \%)$ & $88(55 \%$ & $72(45 \%)$ & $160(100 \%)$ & $24(15 \%)$ & $50(62.5 \%)$. & $80(100 \%)$ & $34(42.5 \%)$ & $46(57.5 \%)$ \\
\hline
\end{tabular}

\subsection{Factors Associated with Adherence/ Nonadherence to Aeds}

Factors that were found to be significantly associated with medication adherence in the univariate analysis are costs of AEDs, no response to AEDs, counseling by local faith healers, side -effects of AEDs, Poor/no counseling by the treating physician(s) and Non availability of $\operatorname{AED}(s)$.

Among the $50 \mathrm{CWE}$ not being treated and followed at TDBUCEC, 28(56\%) reported the cost of their treatment causing nonadherence to their prescribed AEDs, whereas only 2(08.3\%) reported this cause of their nonadherence among CWE being intervened by MCICEC. Uncontrolled seizures were reported associated with $31.5 \%$ of the patients being followed at the center as compared with $12 \%$ nonadherent patients among the control cohort. Misleading and false counseling of local faith healers was significantly associated with nonadherence, more prevalence among the CWE being followed at MCICEC (25\%), as compared with those affording their own treatment (12\%). Additional significant factors Associated with AEDs- adherence/nonadherence are shown in Table-3.

Table3: Reasons for nonadherence to AEDS(s) among children with epilepsyin Bhakhar-Pakistan $(N=74)$

Patients Non-adherent to AED(s) Following at Top-Patients Non-adherent to AED(s) Not Following Down-Bottom-Up Center $(n=24,100 \%)$ at Top-Down-Bottom-Up Center $(n=50,100 \%)$

\begin{tabular}{|l|l|l|l|l|l|l|}
\hline No & $\begin{array}{l}\text { Reasons for non-adherence to No } \\
\text { AED(s) }\end{array}$ & Percentage & Percentage & No \\
\hline 1 & Cost of AED(s) & 02 & 08.3 & 56 & 28 \\
\hline 2 & No response to AED(s & 08 & 33.3 & 12 & 06 \\
\hline
\end{tabular}


Health Care Delivery Model of Childhood Epilepsy to Reduce Treatment Gap in an OutreachFinancially-Constrained District in Pakistan

\begin{tabular}{|l|l|l|l|l|l|}
\hline 3 & Counseling by local faith healers & 06 & 25.0 & 12 & 06 \\
\hline 4 & Side - effects of AEDs & 04 & 16.8 & & 02 \\
\hline 5 & $\begin{array}{l}\text { Poor/no counseling by the treating } \\
\text { physician(s) }\end{array}$ & 08.3 & 10 & 05 \\
\hline 6 & Non availability of AED(s) & 02 & 08.3 & 10 & 03 \\
\hline Total & 24 & 100 & 100 & 50 \\
\hline
\end{tabular}

\subsection{Effect of MCICEC Intervention on Bridging Treatment Gap}

At both camps a total of 240 CWE were diagnosed at least $\geq 3$ months prior to study date. Of the total $160(\%)$ were taking treatment from PHMCICEC and $80(\%)$ had sought care as usual (control) at the time of the study.
At baseline, the two cohorts had similar social demographic and clinical characteristics. All PWE included in the study were suffering from active convulsive epilepsy with either primary or secondary generalization Demographic and clinical characteristics of these groups along source of seeking medical treatment are summarised in Tables 4 and 5.

Table4: Distribution of epileptic children with treatment gap (TG) by age group \& gender in Bhakhar District-Pakistan ( $n=240)$

$\begin{aligned} & \text { Epileptic Patients Following at Top-Down-Bottom-Up Epileptic Patients Not Following at Top-Down - } \\
& \text { Center (n=160, 100\%) } \\
& \text { Bottom-Up Center (n=80,100\%) }\end{aligned}$
\begin{tabular}{|l|l|l|l|l|l|l|l|l|} 
Age group & Male & Female & Total $(\%)$ & TG $(\%)$ & TG $(\%)$ & Total $(\%)$ & Female & Male \\
\hline 2 Mon - 2 yrs & 18 & 15 & $33(20.65 \%)$ & $8 / 35=23 \%$ & $15 / 16=94 \%$ & $16(20 \%)$ & 6 & 10 \\
\hline$>2$ yrs - 5 yrs & 22 & 10 & $32(20 \%)$ & $6 / 26=23 \%$ & $16 / 18=89 \%)$ & $18(22.5 \%)$ & 8 & 10 \\
\hline$>5$ yrs - 10 yrs & 34 & 24 & $58(36.25 \%)$ & $10 / 61=16.4 \%$ & $22 / 26=85 \%)$ & $26(32.5 \%)$ & 12 & 14 \\
\hline$>10$ yrs - 15 yrs & 10 & 15 & $25(15.6 \%)$ & $4 / 25=16 \%$ & $10 / 14=71 \%)$ & $14(17.5 \%)$ & 4 & 10 \\
\hline$>15$ yrs - 18 yrs & 04 & 08 & $12(7.5 \%)$ & $4 / 13=15 \%$ & $3 / 6=50 \%)$ & $06(7.5 \%)$ & 4 & 2 \\
\hline $\begin{array}{l}\text { Total: } \\
160(100 \%)\end{array}$ & $88(55 \%)$ & $72(45 \%)$ & $160(100 \%)$ & $32 / 160=20 \%$ & $66 / 80=82.5 \%$ & $80(100 \%)$ & $34(42.5 \%)$ & $46(57.5 \%)$ \\
\hline
\end{tabular}

A total of 160 CWE being treated and followed at MCICEC 32 (20\%) had previously sought medical treatment that was not according to the guidelines of ILAE [22]. In comparison of the $80 \mathrm{CWE}$, seeking their care as usual (control), $66(82.5 \%)$ were not being treated properly due to various reasons: this means that that $\mathrm{CWE}$ being intervened through PHMCICEC had CETG of $20 \%$, as compared to $82.5 \%$ of such CETG among patients not being intervened through MCICEC and seeking care as usual. Higher percentage of CETG was documented among the children $\leq 5$ years of age (Table-4).
Attributed causes of the TG were multiple and overlapping in most of the cases, however individual predominant causes of CETG are shown in Table-6. These causes were also similar for rural and urban regions. The highest median $(25 \%)$ for each was associated with inadequate skilled manpower and uncontrolled seizures among CWE being intervened through MCICEC. In comparison, poverty $(42.40 \%)$ and inadequate skilled manpower $(24.25 \%)$ were the predominant cause among the control group (Table-5)

Table5: Reasons for Childhood Epilepsy Treatment Gap (CETG) in Bhakhar District (N=98)

\begin{tabular}{|c|c|c|c|c|c|}
\hline \multicolumn{4}{|c|}{$\begin{array}{l}\text { Patients Being Intervened and Following at MCICEC } \\
(\mathrm{n}=32,100 \%)\end{array}$} & \multicolumn{2}{|c|}{$\begin{array}{l}\text { Patients Being not } \begin{array}{l}\text { Intervened and } \\
\text { not Following at MCICEC } \\
(n=66,100 \%)\end{array} \\
\end{array}$} \\
\hline No & Reasons for non-adherence to AED(s) & No & Percentage & Percentage & No \\
\hline 1 & Cost of AED(s) & 02 & 06.25 & 42.40 & 28 \\
\hline 2 & Untrained professionals & 08 & 25 & 24.25 & 16 \\
\hline 2 & No response to $\mathrm{AED}(\mathrm{s}$ & 08 & 25 & 09.10 & 06 \\
\hline 3 & Counseling by local faith healers & 06 & 18.75 & 09.10 & 06 \\
\hline 4 & Side -effects of AEDs & 04 & 12.50 & 03.05 & 02 \\
\hline 5 & $\begin{array}{l}\begin{array}{l}\text { Poor/no counseling by the treating } \\
\text { physician(s) }\end{array} \\
\end{array}$ & 02 & 06.25 & 07.60 & 05 \\
\hline 6 & Non availability of AED(s) & 02 & 06.25 & 04.50 & 03 \\
\hline \multicolumn{2}{|c|}{ Total } & 32 & 100 & \begin{tabular}{|l|}
100 \\
\end{tabular} & 66 \\
\hline
\end{tabular}


Health Care Delivery Model of Childhood Epilepsy to Reduce Treatment Gap in an OutreachFinancially-Constrained District in Pakistan

\section{DISCUSSION}

For many reasons including resource restrictions, simply adopting healthcare guidelines created for higher-resourced areas and using these in resource-limited settings is neither appropriate nor feasible [23].

We propose a package of care, a combination of interventions aimed at improving the recognition and management of conditions to achieve optimal outcomes for childhood epilepsy in 2014 [13, 14]. Limitations in the availability, number, and geographic distribution of specialists trained in the care of childhood epilepsy are a major cause of the delays in accessing care. Several studies have reported that over $90 \%$ of people with epilepsy (PWE) in developing countries do not receive appropriate treatment for their condition, a phenomenon known as the treatment gap (TG) [24]. Similarly in 2014, we documented TGSE of $92 \%$ among children $\leq 18$ years of age in Bhakhar: an outreach financially constrained district in Punjab-Pakistan [14]. The most contributing factors to the epilepsy treatment gap are the following: i) inadequate skilled healthcare manpower, ii) high treatment costs, iii) limited or no antiepileptic drug access, and iv) unfavorable cultural beliefs [25].

The Global Campaign Against Epilepsy, a partnership between the World Health Organization (WHO), International League Against Epilepsy (ILAE) and the International Bureau for Epilepsy (IBE) was launched in 1997 to bring epilepsy "out of the shadows" by addressing some of the factors outlined above [26,2 7].

In 2002, several demonstration projects were set up in various countries, to reduce the TG and the physical, economic and social burden of epilepsy through community-level interventions $[28,29]$. Despite this concerted effort by different stakeholders in different countries, there was no such service for CWE in Bhakhar district. We started top-down-bottom-upchildhood-epilepsy-program [TDBUCEP], which is a multi-component strategy for CWE in outreach financially constrained district. After two years of awareness, educational and treatment free pediatric neurology camps, two years prior to study, we integrated and implemented this program into primary health.

As guidelines are being implemented, program evaluations to assess their operational performance in clinical practice and their effects on care quality should be concurrently planned and budgeted [30]. As in more medically developed countries [31], low-income countries need valid quality indicators for epilepsy care that can adequately assess the effects of guideline implementation. It may be possible to develop such quality indicators even with basic health records in some LAMIC institutions [32]. The clinical care algorithms provided in the mhGAP were developed for use in a wide range of possible low-income and middle- income settings, and therefore must be adapted to local resources and needs, especially if the guidelines are to be used for childhood epilepsy in resource-constrained settings.

Almost universally, developing countries have marked inequalities in the distribution of health care resources (33). Health care in private, settings of these countries may be relatively equivalent to first-world care, but care for the poor is virtually nonexistent. Inequities in the distribution of public services favoring urban regions are also problematic. Neurologists with local experience and knowledge of the culture, who are willing to serve as educators, policy advisors, and advocates, can make a difference. After two years of integration and implementation of this primary health multicomponent interventional childhood epilepsy center (PHMCICEC) into primary health care centre, examined this model's effectiveness in terms of its impact on: 1) treatment coverage and cost-effectiveness of PHMCICEC, 11) effect of PHMCICEC intervention on AEDs adherence and, 111) effect of MCICEC intervention on bridging treatment gap [34].

\subsection{Treatment Coverage and Cost- Effectiveness of MCICEC}

Of the 35 million people with epilepsy who live in developing countries, around $85 \%$ receive no treatment at all $[35,36]$.In many parts of Africa and Asia, notions about epilepsy are rooted not in a medical model but in a spiritual model [37]. In agreement after 4 years of awareness and teaching complains, then after 2 years of integration of childhood epilepsy in primary health care center, we have registered only 2500 $\mathrm{CWE} /$ recurrent seizures of the total approximate 7000 CWE in Bhakhar district. The epilepsy burden is different in Asia, Latin America, and Africa [38], and even within one area there are significant variations in the epidemiology, etiologies, and perceptions of epilepsy in 
Health Care Delivery Model of Childhood Epilepsy to Reduce Treatment Gap in an OutreachFinancially-Constrained District in Pakistan

different geographical regions and communities [39]. Population based neuroepidemiologic studies in different regions of India have shown that epilepsy constitutes nearly a third to a fifth of all neurological disorders, but scarce data is available on childhood epilepsy in outreach districts [40, 41].

We estimated that more than $81 \%$ of the parents of CWE are seeking treatment for their children from Lahore and on the average cost for single consultation and AEDs for one month is 17000 PRS. But, out of this huge amount for poor people 16000 PRS. Are indirect cost. Costeffective epilepsy treatments are available and an accurate diagnosis can be made without technological equipment. Nonetheless, a vast majority of individuals with epilepsy in many resource-poor regions do not receive treatment due to diversities of causes [42-44]. Thus, epilepsy imposes a large economic burden on global health care systems and is a major public health problem in low- and middle-income countries (LMICs) [45]. However, only a very few studies have estimated the cost of epilepsy in these countries [46.47].

In agreement, almost free treatment through MCICEC is being offered and even when the charity money is compared with out of pocket expenses, it is 202 times cost effective. We strongly agree with others that the use of local resources potentially results in high costeffectiveness, particularly in resource-poor settings [48].

Adherence is the degree to which patients' drug taking is consistent with instructions provided by health professionals [49]. AED effectiveness is minimized if prescribed regimens are not followed [50]. Previous studies have reported that $20-60 \%$ of adults with epilepsy are nonadherent to their prescribed AED therapy [5153]. In children however, these rates are even lower estimated between 25 - 75\% [54, 55]. Self report has been the main method of assessing adherence in Low Resource Settings since its affordable and adaptable to study population. In summary, in 2014 we documented $\operatorname{AED}(\mathrm{s})$ nonadherence by self reporting method among $58 \%$ [6] and was still 62\% among CWE without local community intervention [Table-3]. Previous studies have documented a number of factors affecting adherence to antiepileptic drugs such as duration of taking drugs, number of tablets, uncontrolled seizures, believes in faith healers, use of alternative treatment, family support and financial constraints [56-58].
However we documented in 2014 and 2018, that in financially constrained settings cost of AEDs and other medical costs are predominant causes on $\mathrm{AED}(\mathrm{s})$ nonadherence among CWE in these communities, Table-4. In support of this, by provision of free AEDs and pediatric neurology consultation at door steps of $160 \mathrm{CWE}$, believes in faith healers and uncontrolled seizures after commencement of AEDs were the most important causes of nonadherence to AEDs, Table-4. Adherence to antiepileptic drugs in resource limited settings is not well understood. These settings are prone to frequent drug shortages and with the poverty level in these settings, patients and/or caregivers may not always afford purchasing antiepileptic drugs as prescribed. Adherence to antiepileptic drugs may be improved by using a number of interventions such as patient counseling, use of a special medication container, self-recording of medication intake and seizures, and mailed reminders to collect prescription refills and attend clinic appointments [59]. Whereas, in our study integration of childhood epilepsy in local primary health $(\mathrm{PH})$ through multicomponent interventional childhood epilepsy center (MCICEC) empowering the already existing local health system is the best strategy to overall improve the $\mathrm{CE}$ care. This was evidenced that that CWE being followed at local PHMCICEC, being proved free pediatric neurology consultations and AEDs, had AED(s) nonadherence of $15 \%$. As compared to $62 \%$ among the similar CWE (control) not being supported from MCICEC, Table-4.

Our study demonstrates that although estimates of treatment gap among resource-constrained countries are limited, the economic gradient and availability of healthcare and childhood epilepsy-specific resources matter in these countries. The treatment gap, which is defined as the difference between the number of people with active epilepsy and the number whose seizures are being appropriately treated, is high in many LMICs [1]. Overall, 56\% (range 7\%98\%) of PWE in LMICs remain untreated, with $73 \%$ remaining untreated in rural regions compared to $46 \%$ in urban settings [5]. The treatment gap for epilepsy in LMICs for active epilepsy ranges from 25 to $100 \%$, compared to less than $10 \%$ in HICs. There is substantial heterogeneity across and within countries, with treatment gaps higher in rural than urban areas [60-62]. 
Health Care Delivery Model of Childhood Epilepsy to Reduce Treatment Gap in an OutreachFinancially-Constrained District in Pakistan

Similarly, in 2014 we found CETG of $92 \%$ and it was still $82.5 \%$ without local community intervention in Bhakhar- an outreach financially constrained district. Acknowledging epilepsy as a neglected condition by the World Health Organization (WHO) in 2004 has led to increased emphasis on the development of adequate treatment strategies in low- and middle-income countries $[63,4]$.

Specialists not only have a role to play in managing and treating complex cases but they are especially needed to provide education and training, and ongoing supervision and support to non-specialists working at the primary health care level, we adopted the similar principles.

After documentation of huge CETG we started monthly free educational, diagnostic and therapeutic pediatric neurology camps and after integration of $\mathrm{CE}$ in primary health and established PHMCICEC in December 2016. After two years of free provision of AEDs and pediatric neurology consultations, we documented CETG steeply dropped from 92\% to $20 \%$, whereas, the CETG among the control at the study time and in the same population (control) was $82.5 \%$.

It is unlikely that AED could be provided solely by government-funded schemes alone in poor countries. Moreover, private provision of AEDs could cause significant financial hardships to already poor households. Consequently, a large number of those affected go untreated, or are inadequately treated, particularly in developing countries where an estimated 75 to $90 \%$ receive no treatment at all $[65,66]$. While the treatment gap is a very useful global measure for assessing epilepsy care in a given setting, it is also important to recognize its limitations, as the measure alone fails to elucidate anything about the etiology of a high treatment gap.

One of the factors contributing to the treatment gap in epilepsy in LMICs is the lack of a continuous and affordable supply of AEDs [67, 68]. This affirms our findings in which provision of free AEDs through MCICEC in local community improved AEDs adherence to $85 \%$ and CETG dropped steeply from $92 \%$ to $20 \%$. Monthly free pediatric neurology camps and telepediatricneurology support are extremely useful for community awareness, education of medical and paramedical staff and overall monitoring of the project. Evidence is accruing that epilepsy diagnosed using a phone application is possible and this can at least be used as a screening tool in remote, outreach rural communities [69, 70]. Already such projects and documented the success achieved in reducing the epilepsy treatment gap in China by managing convulsive forms of epilepsy at a primary health-care level [71]. As the success of any intervention is a consequence of it being sustainable in the long term, this report also presents the lessons derived for the development of an effective and sustainable framework for epilepsy care and scale-up in resource-poor settings by partnership with already existing local private primary health care in Pakistan.

\section{CONClusion}

Strengthening health system performance is a wide-ranging subject, likely to require action on many fronts and management levels. It requires attention to the various functions of primary health system, especially the various dimensions of management, as well as to associations between the system, its clients (patients), and their communities. Evidence for which approaches work best is limited. The PHMCICEC programs are effective in bridging the childhood epilepsy treatment gap in outreach financiallyconstrained districts and implementing the WHO mhGAP. Poor healthcare infrastructure and high levels of poverty and cultural believes hamper conventional interventions. The combined costeffectiveness and close collaboration with the local charity community primary health allows PHMCICEC to overcome these barriers. Our lessons learned in Bhakhar district may also be applicable to the other outreach financially constrained district in Pakistan, where the CETG is equally high. The indirect costs of epilepsy due to disease and its complications are likely to be very high in developing countries due to the large treatment gap [72]. Treating epilepsy patients at local primary level using MCICEC will increase the treatment coverage and reduce treatment costs. The district care model can help much to lessen the expenditure for travel, food, and lodging and hence the total treatment expenditure for epilepsy. Thus the financial burden on the CWE residents of outreach financially-constrained districts can be greatly reduced. Novel techniques like telemedicine can be implemented as costeffective measure. Option of surgical treatment of epilepsy may also be considered. Ideally, the delivery of these packages should be integrated into existing primary health care with the help of NGOs and other nonmedical staff involved in community-based and mental health care. 
Health Care Delivery Model of Childhood Epilepsy to Reduce Treatment Gap in an OutreachFinancially-Constrained District in Pakistan

\section{REFERENCES}

[1] Meyer, A.-C., Dua, T., Ma, J., Saxena, S., and Birbeck, G. Global disparities in the epilepsy treatment gap: a systematic review. Bull World Health Organ. 2010; 88: 260-266https://doi. org/10.2471/BLT.09.064147

[2] Strzelczyk A, Reese J, Dodel R, Hamer H: Cost of epilepsy. Pharmacoeconomics. 2008, 26 (6): 463-476.10.2165/00019053-200826060-00002. View Article PubMed Google Scholar

[3] Loiseau J, Picot M-C, Loiseau P: Prognosis of Epilepsies Montrouge. John Libbey; 2003, 2938.Google Scholar

[4] Kwan P, Brodie MJ: Early identification of refractory epilepsy. N Engl J Med. 2000, 342 (5): 314-319. 10.1056/NEJM20000203342050 3.

[5] WHO. Epilepsy in the WHO Africa region: bridging the gap: the global campaign against epilepsy: "Out of the shadows," 2004.

[6] WHO. mhGAP intervention guide for mental, neurological and substance use disorders in non-specialized health settings. World Health Organization, ; 2010

[7] Kwan P, Brodie M. Phenobarbital for the treatment of epilepsy in the 21st century: a critical review. Epilepsia 2004; 45: 1141-9 doi: 10.1111/j.0013-9580.2004.12704.x pmid: 1532 9080 .

[8] Chisholm D, WHO-CHOICE. Costeffectiveness of first-line antiepileptic drug treatments in the developing world: a population-level analysis. Epilepsia 2005; 46: 751-9 doi: 10.1111 / j. 1528-1167.2005.52704. x pmid: 15857443 .

[9] Wang WZ, Wu J, Ma G, Dai X, Yang B, Wang $\mathrm{T}$, et al., et al. Efficacy assessment of phenobarbital in epilepsy: a large communitybased intervention trial in rural China. Lancet Neurol 2006; 5: 46-52 doi: 10.1016/S1474-44 22(05)70254-4 pmid: 16361022 .

[10] Kale R. Global Campaign against Epilepsy: the treatment gap. Epilepsia 2002; 43: 31-3 doi: 10. 1046/j.1528-1157.43.s.6.13.x pmid: 12190976.

[11] Begley CE, Baker GA, Beghi E, Butler J, Chisholm D, Langfitt J, et al., et al. Crosscountry measures for monitoring epilepsy care. Epilepsia 2007; 48: 990-1001 doi: 10.111 1/j.1528-1167.2007.00981.xpmid: 17319922.

[12] Diop AG, de Boer HM, Mandlhate C, Prilipko L, Meinardi H. The global campaign against epilepsy in Africa. Acta Trop 2003; 87: 149-59 doi: 10.1016/S0001-706X (03)00038-X pmid: 12781390 .

[13] Malik MA, Shabbir N, Muhammad Saeed, H Malik, Adnan Mirza. Medication Non adherence in Children with Epilepsy Attending
Outpatient Clinics in Under-Resourced Community. J Pediatr Epilepsy 2015; 4:72-79.

[14] Malik MA, Malik H, Wali MW, Shabbir N, Saeed M. Treatment Gap in Childhood Epilepsy (TGCE): Pakistan Regional Study in Under-Resourced Community. J Neurol Psychol. 2015; 3(1): 7. DOI: 10.131 88/2332-3 469.1000017

[15] Li LM, Fernandes P, Noronha A, Marques L, Borges M, Borges $\mathrm{K}$, et al., et al. Demonstration project on epilepsy in Brazil: outcome assessment. ArqNeuropsiquiatr 2007; 65: 58-62 pmid: 17581670.

[16] Wang WZ, Wu J, Ma G, Dai X, Yang B, Wang $\mathrm{T}$, et al., et al. Efficacy assessment of phenobarbital in epilepsy: a large communitybased intervention trial in rural China. Lancet Neurol 2006; 5: 46-52 doi: 10. 1016/S14744422(05)70254-4 pmid: 16361022

[17] WHO. Epilepsy in the WHO Africa region: bridging the gap: the global campaign against epilepsy: "Out of the shadows." 2004.

[18] WHO. MhGAP intervention guide for mental, neurological and substance use disorders in non-specialized health settings. World Health Organization; 2010.

[19] Avanzini G, de Boer HM, De Castro S, Engel J, Lee P, Sabaté E. WHO, Adherence to Long-Term Therapies: Evidence for Action. [Last accessed on 2014 Dec 30]. Available from: http:// www. who.int/chp/knowledge/publications /adherence_ full_report.pdf.

[20] Lisk R, Greene SH. Drug compliance and seizure control in epileptic children. Postgraduate Medical Journal. 1985; 61(715): 401-405.

[21] Meinardi H, Scott RA, Reis R, Sander JW. The treatment gap in epilepsy: the current situation and ways forward. Epilepsia. 2001; 42(1):136-49.

[22] Fisher RS, Cross JH, D'Souza C, et al. Instruction manual for the ILAE 2017 operational classification of seizure types. Epilepsia 2017; 58:531.

[23] Ehrhardt S, Meyer CG: Transfer of evidencebased medical guidelines to low- and middleincome countries. Trop Med Int Health 2012.

[24] Diop AG, Hesdorffer DC, Logroscino G, Hauser WA. Epilepsy and mortality in Africa: a review of the literature. Epilepsia. 2005; 46 (Suppl 11):33-5. [PubMed]

[25] Mbuba, C.K., Ngugi, A.K., Newton, C.R., and Carter, J.A. The epilepsy treatment gap in developing countries: a systematic review of the magnitude, causes, and intervention strategies. Epilepsia. 2008; 49: 1491-1503

[26] Sander JW. Global Campaign Against Epilepsy. Overview of the demonstration 
Health Care Delivery Model of Childhood Epilepsy to Reduce Treatment Gap in an OutreachFinancially-Constrained District in Pakistan

projects. Epilepsia. 2002; 43(Suppl 6):34-6. [PubMed]

[27] Diop AG, de Boer HM, Mandlhate C, Prilipko $\mathrm{L}$, Meinardi $\mathrm{H}$. The global campaign against epilepsy in Africa. Acta Trop. 2003; 87(1):14959. [PubMed]

[28] Sander JW. Global Campaign Against Epilepsy. Overview of the demonstration projects. Epilepsia. 2002； 43(Suppl 6):34-6. [PubMed]

[29] Li LM, Fernandes PT, Noronha AL et al. Demonstration Project on Epilepsy in Brazil: situation assessment. ArqNeuropsiquiatr. 2007; 65(Suppl 1):5-13.

[30] Oxman AD, Schunemann HJ, Fretheim A. Improving the use of research evidence in guideline development: 16. Evaluation. Health Res Policy Syst. 2006; 4:28. doi: 10.1186/14784505-4-28.

[31] Fountain NB, Van Ness PC, Swain-Eng R et al. Report of the Quality Measurement and Reporting Subcommittee of the American Academy of Neurology. Neurology. 2011; 76(1):94-99.

[32] Kvalsund M, Mbewe E, Mulenga $\mathrm{J}$ et al. Quality indicators for epilepsy care in Zambia: Roadwork for the WHO Mental Health Gap Action (mh GAP) program. American Academy of Neurology Annual Meeting 2012 P07116, April 2012 2012; New Orleans. 2012.

[33] Begley CE, Baker GA, Beghi E, Butler J, Chisholm D, Cross-country measures for monitoring epilepsy care. Epilepsia. 2007 May; 48(5):990-1001.

[34] Li LM, Fernandes PT, Noronha AL, Marques LH etal. Demonstration Project on Epilepsy in Brazil: situation assessment. Arq Neuro psiquiatr. 2007; 65(Suppl 1):5-13. [PubMed]

[35] Kale R. Global Campaign Against Epilepsy: the treatment gap. Epilepsia. 2002; 43 Suppl 6():31 -3 .

[36] World Health Organization, International Epilepsy Bureau and International League against Epilepsy. Atlas. Epilepsy Care in the World 2005. Geneva: WHO, 2005

[37] Whyte SR (1995) Constructing epilepsy: images and contexts in East Africa. Disability and culture. Whyte SR, Ingstad B, eds. Berkeley: University of California Press. pp 226-245.

[38] Yemadje LP, Houinato D, Quet F, DruetCabanac M, Preux PM: Understanding the differences in prevalence of epilepsy in tropical regions. Epilepsia 2011, 52(8):1376-1381.

[39] Preux PM, Druet-Cabanac M: Epidemiology and aetiology of epilepsy in sub-Saharan Africa. Lancet Neurol 2005, 4(1):21-31.
[40] Nelson Lorene M. Neuroepidemiology-From Principles to Practice. 1st edition. London, UK: Oxford University Press; 2003.

[41] Sridharan R, Murthy BN. Prevalence and pattern of epilepsy in India. Epilepsia. 1999; 40(5):631-636.

[42] Kwan P, Brodie M. Phenobarbital for the treatment of epilepsy in the 21st century: a critical review. Epilepsia 2004; 45:1141-9. doi:10.1111/j.0013- 9580.2004.12704.x PMID: 15329080

[43] Chisholm D; WHO-CHOICE. Costeffectiveness of first-line antiepileptic drug treatments in the developing world: a population-level analysis. Epilepsia 2005; 46: 751-9. doi:10.1111/j.1528-1167.2005.527 04.x PMID:15857443

[44] Wang WZ, Wu J, Mrrt6a G, Dai X, Yang B, Wang $T$ etal. Efficacy assessment of phenobarbital in epilepsy: a large communitybased intervention trial in rural China. Lancet Neurol 2006; 5:46-52. doi:10.1016/S14744422(05)70254-4PMID :16361022

[45] World Health Organisation (WHO) (2005) Atlas: epilepsy care in the world. Geneva: WHO.

[46] Chandra B. Economic aspects of epilepsy in Indonesia. In Beran RG, Pachlatko C(ed) Cost of epilepsy. Baden: Ciba GeigyVerlag, 1995; 75-82. FandinoFranky J \&Silfvenius H. World wide disparities in epilepsy care: a Latin American outlook. Epilepsia 1999; 40(Suppl 8):48-54.

[47] Thomas SV, Ramankutty V, Alexander A. Management and Referral Patterns of Epilepsy in India. Seizure 1996; 5:303-306

[48] LaFrance WC, Jr., Kanner AM, Hermann B. Psychiatric comorbidities in epilepsy.Int Rev Neurobiol 2008; 83: 347-383.

[49] Paschal AM, Rush SE, Sadler T. Factors associated with medication adherence in patients with epilepsy and recommendations for improvement. Epilepsy Behav. 2014; 31:34650. [PubMed]

[50] Faught E, Duh MS, Weiner JR, Guerin A, Cunnington MC. Nonadherence to antiepileptic drugs and mortality: findings from the RANSOM Study. Neurology. 2008; 71:1572-8. [PubMed]

[51] Davis KL, Candrilli SD, Edin HM. Prevalence and cost of nonadherence with antiepileptic drugs in an adult managed care population. Epilepsia. 2008; 49:446-454. [PubMed]

[52] Jones RM, Butler JA, Thomas VA, Peveler RC, Prevett M. Adherence to treatment in patients with epilepsy: associations with seizure control and illness beliefs. Seizure. 2006; 15:504-8. [PubMed] 
Health Care Delivery Model of Childhood Epilepsy to Reduce Treatment Gap in an OutreachFinancially-Constrained District in Pakistan

[53] Goodman MJ, Durkin M, Forlenza J, Ye X, Brixner DI. Assessing adherence-based quality measures in epilepsy. Int $\mathbf{J}$ Qual Health Care. 2012; 24:293-300. [PubMed]

[54] WHO. Geneva: World Health Organization; 2003. Adherence to long term therapies, evidence for action.

[55] Durón M Reyna, Medina TM, Nicolás O, Varela EF, Ramírez F, Battle J Sean. Adherence and complementary and alternative medicine use among Honduran people with epilepsy. Epilepsy \& Behavior. 2009; 14 (4): 645-650.

[56] Eatock Joanne, Baker AG. Managing patient adherence and quality of life in epilepsy. Neuropsychiatric Disease and Treatment. 2007; 3(1):117-131.

[57] Cramer A Joyce, Glassman M, Rienzic V. The relationship between poor medication compliance and seizures. Epilepsy \& Behavior. 2002; 3(4):338-342.

[58] Al-Faris A Eiad, Abdulghan MH, Mahd HA, Salih AM, Al-Kordi GA. Compliance with appointments and medications in a pediatric neurology clinic at a University Hospital in Riyadh, Saudi Arabia. Saudi Medical Journal. 2002; 23(8):969-974.

[59] Peterson GM, McLean S, Millingen KS. A randomised trial of strategies to improve patient compliance with anticonvulsant therapy. Epilepsia. 1984; 25(4):412-417.

[60] Newton CR, Garcia HH. Epilepsy in poor regions of the world.Lancet.2012; 380:1193201.

[61] Meyer A-C, Dua T, Ma J, Saxena S, Birbeck G. Global disparities in the epilepsy treatment gap: a systematic review. Bull World Health Organ. 2010; 88:260-6.

[62] Mbuba CK, Ngugi AK, Newton CR, Carter JA. The epilepsy treatment gap in developing countries: a systematic review of the magnitude, causes, and intervention strategies. Epilepsia. 2008; 49:1491-503.

[63] WHO. Epilepsy in the WHO Africa region: bridging the gap: the global campaign against epilepsy: "Out of the 4. shadows."; 2004

[64] WHO. mhGAP intervention guide for mental, neurological and substance use disorders in non-specialized health settings. World Health Organization; 2010

[65] WHO (2003a) "Adherence to long-term therapies: evidence for action" A report of the adherence to long-term project, $\mathrm{WHO} / \mathrm{MNC} / 03.01$

[66] Coleman et al (2002) "The treatment gap and primary health care for people with epilepsy in rural Gambia" Bulletin of the World Health Organization 2002; 80:378-383.

[67] Scott RA, Lhatoo SD, Sander JW (2001) The treatment of epilepsy in developing countries: where do we go from here? Bull World Health Organ 79: 344-351.

[68] ILAE (1985) Availability and distribution of antiepileptic drugs in developing countries. III and IV Commissions on Antiepileptic Drugs of the International League Against Epilepsy. Epilepsia 26: 117-121.

[69] Patterson V. Singh M. Rajbhandari H. Vishnubhatla S. Validation of a phone app for epilepsy diagnosis in India and Nepal. Seizure 30, 2015, 46-49

[70] Paul P. Agarwal M. Bhatia R. Vishnubhatla S. Singh MB: Nurse-led epilepsy follow-up clinic in India: is it feasible and acceptable to patients? A pilot study. Seizure; 2014;23(1): 74-6

[71] Epilepsy Management at Primary Health Level in rural China: WHO/ILAE/IBE a Global Campaign against Epilepsy Demonstration Project. Epilepsy management in rural China. World Health Organization 2009

[72] Thomas SV, Sarma PS, Alexander M, et al. Economic burden of epilepsy in India. Epilepsia. 2001; 42(8):1052-1060.4.

Citation: Muhammad Akbar Malik, Nadeem Shabbir, Arshad Rafiq, Ahmad Omar Virk. Health Care Delivery Model of Childhood Epilepsy to Reduce Treatment Gap in an Outreach-Financially-Constrained District in Pakistan. ARC Journal of Neuroscience. 2019; 4(1):1-14. doi: dx.doi.org/10.20431/2456-057X 0401001.

Copyright: (C) 2019 Authors. This is an open-access article distributed under the terms of the Creative Commons Attribution License, which permits unrestricted use, distribution, and reproduction in any medium, provided the original author and source are credited. 